\title{
Ensuring Trading Strategies Profitability with Technical Analysis Tools and Computer Technology
}

\author{
G.Abuselidze ${ }^{1, *}, A$. Slobodianyk $^{2}$, and $N$. Reznik $^{2}$ \\ * Corresponding author: abuseri@mail.ru. \\ ${ }^{1}$ Batumi Shota Rustaveli State University, Batumi, Georgia \\ ${ }^{2}$ National University of Life and Environmental Science of Ukraine, Kiev, Ukraine
}

\begin{abstract}
The paper is devoted to the study of the tools of technical analysis using computer technology. It analyzes the current conditions and the essence of the stock market, the basis of its functioning. The advantages of technical analysis are presented including accessibility and relative simplicity of its use. It analyzes the main indicators of the world stock market development and modern constant signs and tendencies of the process. It is revealed that the improvement of the technical analysis and increase of the forecast accuracy is a complex process. The prospects for the effective use of technical analysis in trading strategies for promoting analysis by using historical data of price changes for the asset under study by using computer software are determined. Back testing calculations are presented making clear the fact that the financial result would be given by a trading strategy based on the historical profitability of the asset.
\end{abstract}

Keywords: technical analysis, fundamental analysis, stock market, trading strategies, average flow method, back testing.

\section{Introduction}

The transition to the information society sets a number of fundamentally new challenges for the economic science. One of these tasks is to provide the participants of exchange activities with high-quality and timely information, because information in modern conditions is one of the key resources.

A unique source of this information is exchange markets, which, due to the asset prices, signal on the condition and prospects of the global economic system development. In order to ensure the freedom of the activity of any market, it is necessary to analyze it. The precise understanding of the market situation, the ability to forecast market behavior, the analysis of its mood leads to an informed decision-making.

The only question concerning the participants of the exchange activity is how to make a high-quality forecast and achieve a competitive advantage over others. The most common approaches in the environment of exchange practice are considered to be technical and fundamental analysis.

\section{Methods}

The problems of the world market and the implementation of technical and fundamental analysis were studied in the works of the following scientists: G. Abuselidze, A. Slobodianyk [1, 2], S.V. Arzhenovsky, I.N. Molchanov [3], E.H. Nyman [4] and A.N. Sokhatskaya [5]. The reason for such attention on the part of scientists is the extreme problem actuality as well as the rapid development of monetary relations requiring the detailed study of the market. According to V.V. Acharya and T.C. Johnson [6], asymmetric information and insider trading problems potentially exist in most markets. But the credit derivatives market may be especially vulnerable since, almost by definition, most of the major players are insiders. Insider trading has been the focus of a large body of research in equity markets which has found that insider trading lowers liquidity and increases trading costs (see, e.g., D. Easley, N.M. Kiefer, M. O'Hara, and J.B. Paperman [7], J.C. Bettis, J.L. Coles, and M.L. Lemmon [8], P. Brockman and D.Y. Chung [9], R.P.H. Fishe and M.A. Robe [10], raises the cost of equity capital [11], and increases volatility [12]). Theoretical and methodological bases of the research are scientific works of domestic and foreign scientists in the field of exchange trade, statistics, mathematical modeling. The following methods are used in the paper: descriptive and comparative analysis, synthesis, scientific abstraction, economic-statistical, fundamental, technical analysis.

\section{Discussion and Results}

The study of the dynamics of the world stock markets associated with the processing of the large amount information based on various data having a rather complex internal structure. The process of improving technical analysis and increasing the accuracy of the forecasts is a complex process and the result can fluctuate only within a limited framework of the technical analysis. Firstly, there is a large number of false signals generated by tools of technical analysis. The number of false signals can be reduced within the framework of the technical analysis methodology, but it is impossible to avoid them completely [1]. Secondly, the methods of technical analysis do not 
allow to create high-quality long term forecasts, the time horizon of technical analysis is short and medium-term forecasts.

The main task of monitoring the stock market situation is to determine the set of circumstances determining the possibility of a rise or fall in market activity. It is reduced to the formulation and solution of the problem of forecasting the dynamics of asset prices.

Research of the stock market dynamics associated with the processing of large information arrays of various data with a fairly complex internal structure. Moreover, the analysis of the information is based on the implementation of a large number of routine calculations, graphical constructions, providing for the assumption of different levels of the errors and taking a long time in their processing. It is possible to overcome these difficulties by means of computer technology using specialized services and programs.

Each analyst applies technical analysis, forming own decision-making methodology and creating own method of technical analysis, absorbing individual elements of the well-known foundations of technical analysis. It is considered that if the created model allows you to get the correct forecast in $60 \%$ of cases, then this research technique is effective and is characterized by high accuracy.

The effectiveness of using technical analysis in trading strategies can be analyzed by using historical data on price changes for the studied asset by using MS Excel software or specialized services. The implementation of such an analysis is called back testing. Back testing makes it clear that a trading strategy based on the historical profitability of an asset would give a financial result. In back testing we will analyze two strategies: a passive investment strategy Buy \& Hold and an active investment strategy using two averages with periods of 50 and 200 days. The Buy \& Hold strategy ("Buy and Hold") provides for the purchase of an asset with the purpose of its long-term maintenance with the expectation of a price growth. The strategy is based on the idea that the global long-term trend is always ascending.

As a rule, when using this strategy, it is not planned to fix losses in case the market moves down. In this case the expected return on capital is usually ten or even hundred percent. The basis of an average flow strategy is to receive a buy signal in case the price of the asset starts to rise and a sell signal when the price starts to decline. In long-term investment strategies, average sized flows with a period of 50 and 200 days are most often used for this purpose.

Taking into consideration the fluctuations in exchange rates that were in this period, the yield of $13.49 \%$ is leveled by a decrease in the purchasing power of the national currency in relation to the US dollar. At the beginning of 2007 , the USD/UAH exchange rate was 5.05, at the end of October 2018, the USD/UAH exchange rate was 28.05 [13] and the USD/GEL exchange rate was 1.65, at the end of October 2018, the USD/GEL exchange rate was 2.80 [14]. Taking into consideration the precarious political and economic stability in Ukraine or Georgia and the lack of a stable exchange rate, long-term investment in the Georgian and Ukrainian stock markets is not attractive enough for foreign investors.

The main objective of an active investment is to reduce the risks associated with the fall in the value of the asset and obtain a higher return in the long term compared to the average return of the stock market. The use of technical analysis, namely secondary flow with a period of 50 and 200 days allows you to avoid losses arising from the use of Buy \& Hold strategies, as with medium flowing there is a possibility to receive a signal about a reduced value of the asset and to limit losses by selling the asset before its price will continue to decline. Fig. 1 shows the price chart of SPY with the use of average flows.

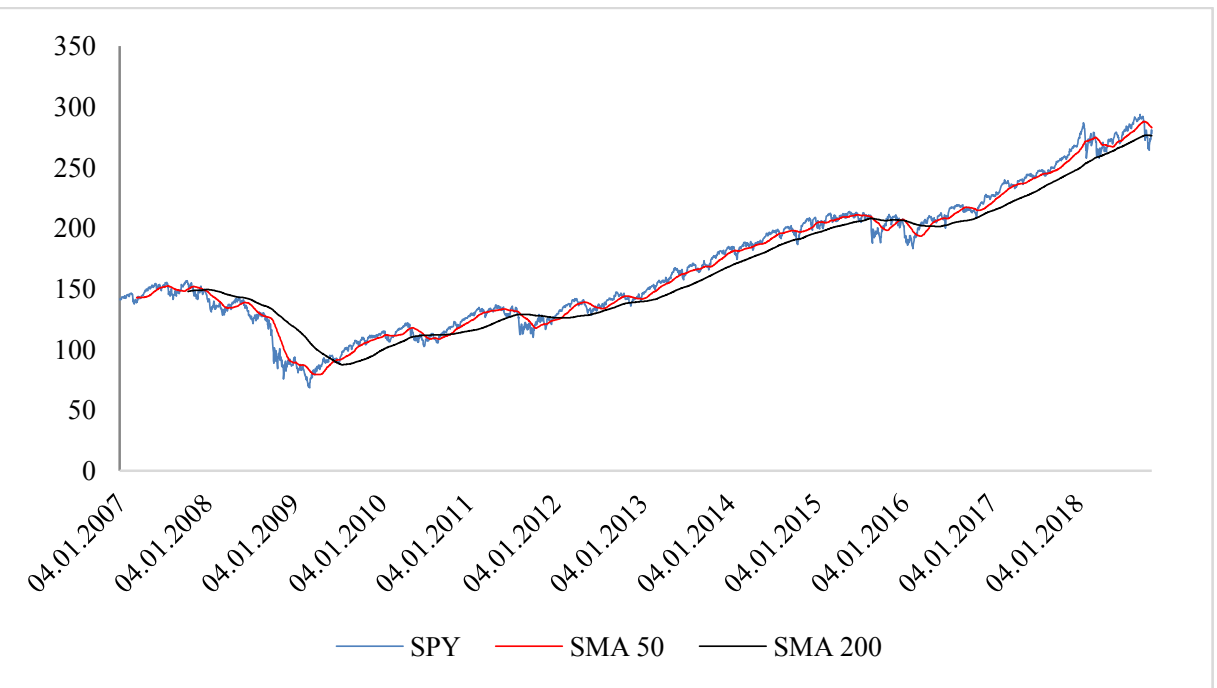

Fig. 1. ETF SPY Chart period from 2007 to 2018 using the average flow. Source: Authors based on historical data [15].

According to Fig. 1 it can be seen that in the period from 2007 to 20185 signals were received to buy an asset and 5 signals to close a position. For a more detailed analysis of the strategy using flow averages, consider the chart of its profitability compared to the Buy \& Hold strategy in Fig. 2. 


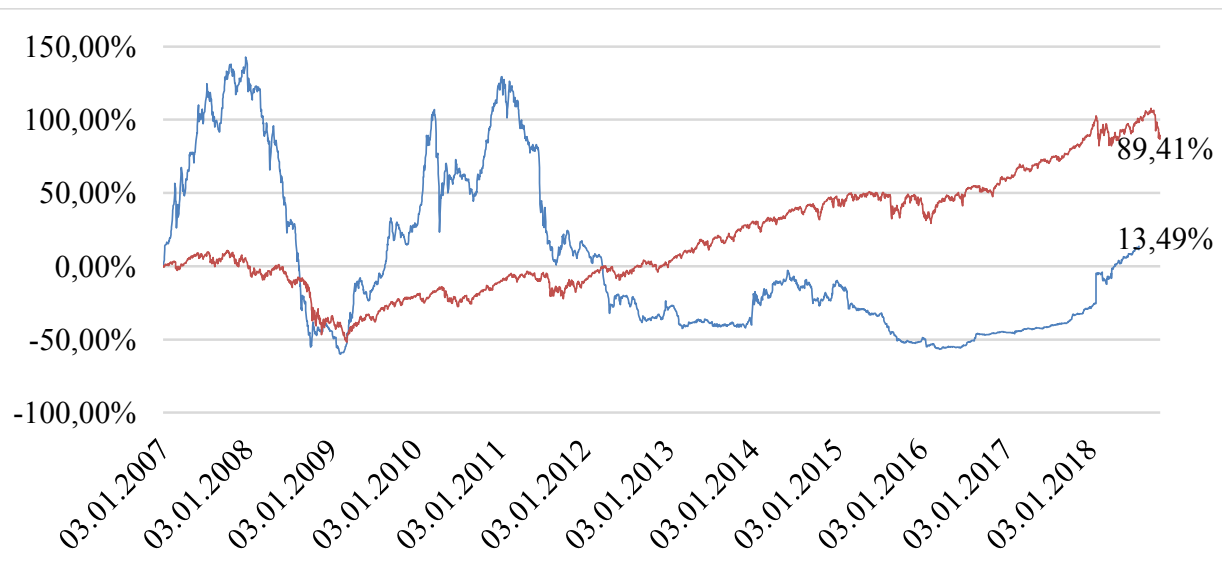

Fig. 2. Yield chart strategies using two average flows for ETF SPY for the years 2007-2018. Source: Authors based on historical data [15].

Having considered Fig. 2 it can be seen that the use of medium flow reduces the risk of investments. So, compared to the Buy \& Hold strategy, the maximum decrease in asset value was only $-8.62 \%$, and the final profit due to the use of technical analysis was $101.53 \%$. Compared to the Buy \& Hold strategy, this is $12.12 \%$ higher.

Thus, the use of technical analysis in the future allows you to increase the profitability of trading strategies meanwhile reducing market risks associated with a decrease in the value of the asset. Fundamental and technical analyses have their advantages and disadvantages. Therefore, in order to conduct analysis of the economy of the country as a whole or of an individual company, it is necessary to carry out both fundamental and technical analysis. This will provide the greatest economic effect in the implementation of exchange operations.

\section{Conclusions}

The modern world stock market today is in a state of continuous transformation of the organizational structure of exchanges, exchange trading technology, exchange instruments, types of basic assets. From year to year, there is a tendency to increase trading volumes on stock exchange markets, especially Asian exchange markets, occupying the largest share in the world stock exchange trading. An objective implementation of fundamental analysis implies a transparent market economy, perfect legislation, political and economic stability of the country. When trading in any market, including the stock market, systematicity is important. For maximum profitability and stability, it is necessary to use a combination of technical and fundamental analysis. In order to improve technical analysis and increase the accuracy of forecasts, it is necessary to go through a complex process and the result can fluctuate only in a limited framework of the possibilities of technical analysis. The study of the dynamics of world markets is associated with the processing of large information arrays of various data. These difficulties can be overcome through the use of computer technology.

\section{References}

1. G. Abuselidze, A. Slobodianyk, Investment of the financial instruments and their influence on the exchange stock market development. In A. Auzina (Ed.), Proceedings of the International Scientific Conference Economic Science for Rural Development, 52, 203-210 (2019).

2. G. Abuselidze, Georgia's capital market: Functioning problems and development directions in association with European Union. Journal of Applied Economic Sciences, 13(7), 1929-1938 (2018).

3. S.V. Arzhenovsky, I.N. Molchanov, Statistical forecasting methods (RSEU, Rostov-on-Don, 2001). [in Rus.].

4. E.H. Nyman, Small encyclopedia of trader (Kiev Logos, Kiev, 1971).

5. A.N. Sokhatskaya, Exchange business (carte Blanche, Moscow, 2009).

6. V.V. Acharya, T.C. Johnson, Insider trading in credit derivatives. Journal of Financial Economics, 84(1), 110-141 (2007).

7. D. Easley, N.M. Kiefer, M. O’Hara, J.B. Paperman, Liquidity, information, and infrequently traded stocks. The Journal of Finance, 51(4), 1405-1436 (1996). DOI: 10.2307/2329399.

8. J.C. Bettis, J.L. Coles, M.L. Lemmon, Corporate policies restricting trading by insiders. Journal of Financial Economics, 57(2), 191-220 (2000). DOI: 10.1016/S0304-405X(00)00055-6.

9. P. Brockman, D.Y. Chung, Investor protection and firm liquidity. The Journal of Finance, 58(2), $921-937$ (2003).

10. R.P.H. Fishe, M.A. Robe, The impact of illegal insider trading in dealer and specialist markets: Evidence from a natural experiment. Journal of Financial Economics, 71(3), 461-488 (2004). DOI: 10.1016/S0304-405X(03)00188-0.

11. U. Bhattacharya, H. Daouk, The world price of insider trading. The Journal of Finance, 57(1), 75-108 (2002). 
12. J. Du, S.-J. Wei, Does insider trading raise market volatility? The Economic Journal, 114(498), $916-942$ (2004). DOI: $10.1111 /$ j.1468-0297.2004.00249.x.

13. National Bank of Ukraine, Official exchange rate of Hryvnia (2019). URL: https://bank.gov.ua/control/en/. Accessed: 15.08.2019.

14. National Bank of Georgia, Official exchange rate of LARI (2019). URL: https://www.nbg.gov.ge/index.php?m=582\&lng=eng. Accessed: 15.08.2019.

15. Nasdaq, SPY S \& P 500 Index (2019). URL: https://new.nasdaq.com/market-activity/funds-and-etfs/spy. Accessed: 15.08.2019. 